\title{
Effect of Frying Treatments on Texture and Colour Parameters of Deep Fat Fried Yellow Fleshed Cassava Chips
}

\author{
A. B. Oyedeji, ${ }^{1}$ O. P. Sobukola, ${ }^{2}$ Folake Henshaw, ${ }^{2}$ M. O. Adegunwa, ${ }^{3}$ O. A. Ijabadeniyi, \\ L. O. Sanni, ${ }^{2}$ and K. I. Tomlins ${ }^{4}$ \\ ${ }^{1}$ Department of Biotechnology and Food Technology, Durban University of Technology, Durban, South Africa \\ ${ }^{2}$ Department of Food Science and Technology, Federal University of Agriculture, Abeokuta, Nigeria \\ ${ }^{3}$ Department of Hospitality and Tourism, Federal University of Agriculture, Abeokuta, Nigeria \\ ${ }^{4}$ Natural Resources Institute, University of Greenwich, London, UK
}

Correspondence should be addressed to A. B. Oyedeji; jibanky2@gmail.com

Received 14 February 2017; Accepted 29 March 2017; Published 4 May 2017

Academic Editor: Latiful Bari

Copyright (C) 2017 A. B. Oyedeji et al. This is an open access article distributed under the Creative Commons Attribution License, which permits unrestricted use, distribution, and reproduction in any medium, provided the original work is properly cited.

\begin{abstract}
Effects of frying treatments on texture (hardness) and colour parameters $(L, a, b, \Delta E)$ during deep fat frying of yellow fleshed cassava root slices (TMS 01/1371) were investigated. Slices (dimension of $40 \mathrm{~mm} \times 25 \mathrm{~mm} \times 3 \mathrm{~mm}$ ) were divided into three portions and subjected to vacuum frying (fresh slices) and atmospheric frying (fresh and predried slices) and equivalent thermal driving forces (ETDF) of $60^{\circ} \mathrm{C}, 70^{\circ} \mathrm{C}$, and $80^{\circ} \mathrm{C}$ were maintained during frying. The quality attributes investigated were best preserved in vacuum fried chips. The overall colour change in chips fried under vacuum conditions at $118^{\circ} \mathrm{C}$ and 8 min was the least (21.20) compared to fresh and atmospherically predried ones (16.69 and 14.81, resp.). A sharp reduction in the breaking force was obtained for all frying treatments after $8 \mathrm{~min}$ and this effect was the least in vacuum fried chips. First-order kinetics modeled the changes in quality attributes for all the temperatures investigated. Rate constants $k\left(\mathrm{~min}^{-1}\right)$ obtained for vacuum frying were almost equal to that of atmospheric frying while activation energies for hardness and colour change were 53.30 and $467.11 \mathrm{KJ} / \mathrm{mol}$, respectively. Quality attributes studied were best preserved during vacuum frying.
\end{abstract}

\section{Introduction}

Frying as a complex unit operation is essentially a cooking process that has been widely used in the food industry. Traditionally, it involves the immersion of foods in frying oil chambers, mostly at temperatures above the boiling point of water, bringing about a counter-flow of water bubbles and oil on the surface of the product [1]. Texture is a quality attribute which is important in determining the acceptability of fried products as the resulting texture of fried foods is dependent on the properties of raw materials such as starch content, size of starch granules, cell wall polysaccharides, nonstarch polysaccharides, pectin substances, and the processing conditions which include frying time and temperature [2]. Hardness is a key texture parameter and it depends on physical and chemical changes such as release of intracellular materials, starch gelatinization, dehydration, crust formation, breakdown of adhesive forces between cells, water evaporation, and tissue expansion [3]. The resulting colour of foods processed in a high heat unit operation is also a major quality attribute as it plays an important role in the perception of consumers about the foods at the point of purchase. Parameters of colour such as lightness $(L)$, redness $(a)$, and yellowness $(b)$ have been widely used in recent times to evaluate colour changes between the raw food materials and final products [4].

Deep fat frying is traditionally carried out at atmospheric pressure conditions and high temperatures of up to $180^{\circ} \mathrm{C}$ (atmospheric frying). However, it had been proven that frying under atmospheric conditions leads to loss of desirable colour and textural characteristic of the resulting products [5]. This could be attributed to destruction of colour components of foods and excessive crust formation due to high frying temperatures. Prefrying treatments aimed at improving the resulting colour and texture of fried food products had earlier been investigated. Califano and Calvelo [6] used blanching as 
a prefrying treatment in potato chips to improve the colour and texture of the resulting products while Krokida et al. [7] used predrying to improve these quality attributes. Vacuum frying had been employed as a frying method aimed at preserving the quality attributes of fried foods because it is carried out at reduced atmospheric pressure conditions and hence lower frying temperatures [8].

Since frying leads to changes in quality attributes in fried food products, Hindra and Baik [9] reported that the study of kinetics of these changes during frying is of critical importance because the knowledge of kinetic parameters during the process will help to predict the final quality changes and permit improvement of product value through proper selection of processing conditions. Vitrac et al. [10] studied the kinetics of colour changes in fried chips obtained from white fleshed cassava, Nourian and Ramaswamy [2] and Nourian and Ramaswamy [4] studied the kinetics of change in texture and colour parameters during frying of potato chips, and Odenigbo et al. [11] studied the kinetics of changes in quality attributes during frying of different cultivars of potato. However, information on kinetics of changes in texture and colour parameters in deep fat fried yellow fleshed cassava chips is scarce in literature.

The objective of this research is to study the effect of changes in frying treatments on the texture and colour parameters during deep fat frying of yellow fleshed cassava chips and to specifically investigate changes in these quality attributes at each frying time for vacuum and atmospheric frying, determine kinetic parameters for these changes, and evaluate the activation energies for changes of these quality attributes with respect to each frying treatment.

\section{Materials and Methods}

We followed the methods of [12]. Healthy and freshly harvested YFCR (TMS 01/1371) were obtained from the International Institute of Tropical Agriculture, Ibadan, Nigeria, and palm olein used for frying was sourced from a local market in Abeokuta, Nigeria.

2.1. Sample Preparation. The yellow fleshed cassava roots were peeled, washed, and carefully sliced using very sharp stainless steel knives into a regular rectangular shape with the dimension $40 \mathrm{~mm} \times 25 \mathrm{~mm} \times 3 \mathrm{~mm}$. Samples were divided into three portions where the first two were fried under vacuum and atmospheric conditions while the third portion was predried to $75 \%$ of the initial moisture content in a cabinet drier before atmospheric frying.

\subsection{Frying Experiments}

2.2.1. Atmospheric Frying Experiments. Twenty (20) slices per sample were placed inside the frying basket of deep fat fryer (Bush Domestic FCO300, UK) and were covered with a metal lid in order to prevent floatation of samples in the frying oil during frying. Frying was carried out at $160^{\circ} \mathrm{C}, 170^{\circ} \mathrm{C}$, and $180^{\circ} \mathrm{C}$ for 2 to 12 minutes. This was done for fresh slices and also for predried samples. After each frying time, the samples were packaged in Ziploc packaging films for further analyses.
TABLE 1: Experimental conditions for atmospheric and vacuum frying treatments.

\begin{tabular}{lccc}
\hline Frying conditions & \multicolumn{3}{c}{ Temperatures $\left({ }^{\circ} \mathrm{C}\right)$} \\
\hline Atmospheric & 160 & 170 & 180 \\
Vacuum $(8.5 \mathrm{mmHg})$ & 108 & 118 & 128 \\
ETDF & 60 & 70 & 80 \\
\hline
\end{tabular}

ETDF: equivalent thermal driving force.

2.2.2. Vacuum Frying. Twenty (20) samples were placed inside the frying basket of vacuum fryer (Model: VF 30, Agrindo Cipta Mandiri, Indonesia). To achieve this, the pressure of the fryer was set at $8.5 \mathrm{mmHg}$ equivalent to $48^{\circ} \mathrm{C}$ boiling point of water and was maintained throughout the vacuum frying experiments. Frying was carried out at $108^{\circ} \mathrm{C}, 118^{\circ} \mathrm{C}$, and $128^{\circ} \mathrm{C}$ for 2 to $12 \mathrm{~min}$. This was done for fresh slices alone. These experimental conditions are as presented in Table 1. In order to compare samples fried under both atmospheric and vacuum conditions, the concept of equivalent thermal driving force (ETDF) was used. ETDF is the difference between the frying oil temperature and the boiling point of water at the working pressure.

\subsection{Analyses of Samples}

2.3.1. Texture Analysis. Maximum breaking force of fried chips was determined in a Texture Analyser TA.XT (Stable Micro System, Surrey, UK) using the method described by $[3]$.

\subsubsection{Colour Analysis}

Image Acquisition and Capture. As used by Mariscal and Bouchon [5], images of fried samples were captured using a colour digital camera model PowerShot A70 (Canon USA) placed on the perforated surface of a large box impervious to light with internal black surfaces. The lighting system inside the box consisted of four CIE source D65 lamps $(60 \mathrm{~cm}$ length and $18 \mathrm{~W}$ ) placed above the samples at $45^{\circ}$ angle to maximize diffuse reflection responsible for colour. The angle between the camera and the lens axis and the sample was maintained around $90^{\circ}$ to reduce gloss. Images were acquired after frying. High resolution images acquired were stored in JPEG (Joint Photographic Experts Group) format in RGB colour coordinates. Thereafter, RGB colour images were converted to lab values using Adobe Photoshop CS6 software (Adobe System Inc., San Francisco, USA), where $L^{*}$, $a^{*}$, and $b^{*}$ values were obtained according to the equations below:

$$
\begin{aligned}
L^{*} & =\frac{L}{255} \times 100, \\
a^{*} & =a \times \frac{240}{255}-120, \\
b^{*} & =b \times \frac{240}{255}-120 .
\end{aligned}
$$


Also, from $L, a$, and $b$ values obtained, the colour change $\Delta E$ was obtained using the relation:

$$
\Delta E^{*}=\left[\left(L_{o}^{*}-L^{*}\right)^{2}+\left(a_{o}^{*}-a^{*}\right)^{2}+\left(b_{o}^{*}-b^{*}\right)^{2}\right]^{1 / 2} .
$$

2.4. Kinetics of Changes in Texture and Colour Parameters. First-order equation (3) was applied in modeling the changes in the texture parameter while colour properties were modeled using modified first-order equation (4). Arrhenius graphs were also plotted and the activation energies for each frying methods were determined (5).

First-order kinetics equation:

$$
\ln \frac{d P}{P}=k t .
$$

Modified first-order equation:

$$
\ln \frac{\left(P_{t}-P_{\min }\right)}{\left(P_{\max }-P_{\min }\right)}=k t .
$$

Arrhenius equation:

$$
\ln k=-\left[\frac{E_{a}}{R T}\right]\left[\frac{1}{T}\right]+\ln k_{o},
$$

where $P$ is the quality attribute, $k$ is the first-order rate constant $\left(\min ^{-1}\right), t$ is the frying time, $E_{a}$ is the activation energy $(\mathrm{kJ} / \mathrm{mol}), R$ is gas constant $\left(\mathrm{J} \mathrm{K}^{-1} \mathrm{~mol}^{-1}\right), T$ is temperature (Kelvin), and $k_{o}$ is frequency factor.

2.5. Data Analysis. Statistical analysis was carried out on the data obtained using data fit version 9.0 (Oakdale Engineering, 2008). Experimental data obtained were fitted into the firstorder kinetics model and the applicability of the model was ascertained with $R^{2}$ values obtained being close to 1 . Significant differences $(p<0.05)$ were ascertained at $5 \%$ level in the quality attributes for different frying conditions using SPSS version 16.0.

\section{Results and Discussions}

3.1. Texture Parameter (Hardness). The textural properties of fried starch based products are influenced by gelatinization of starch, sugar content, and the strength of the cell wall [13]. In this study, the parameter of texture measured is hardness and is indicated by the breaking force $(\mathrm{N})$. As presented in Figure 1, a rapid increase in the breaking force was observed at lower frying times for all frying methods used. The increase could be a result of rapid moisture loss on the surface of fried chips. During food frying, loss of surface moisture brings about dehydration of crusts, which results in increase in hardness of foods [14].

A rapid decrease in the maximum breaking force was noticed from frying times of $8-12 \mathrm{~min}$. for all frying treatments (Figure 1). This sharp decrease was most prominent in predried atmospheric fried chips. Sharp decrease in breaking

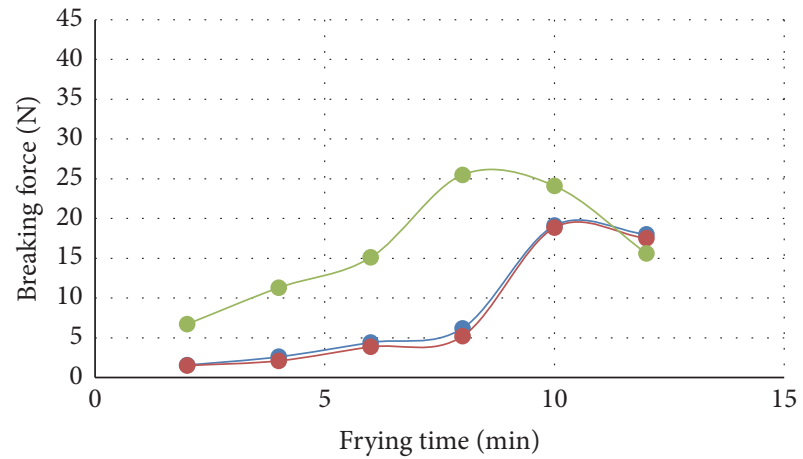

- Vacuum

- Atmospheric fresh

- Atmospheric predried

(a)

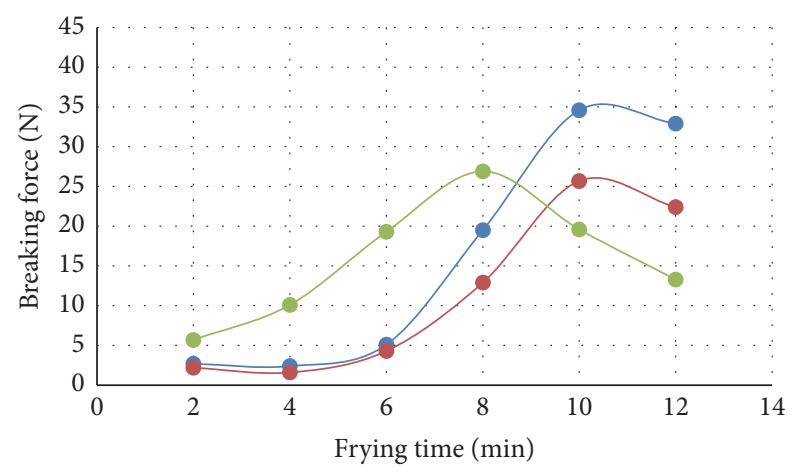

- Vacuum

- Atmospheric fresh

- - Atmospheric predried

(b)

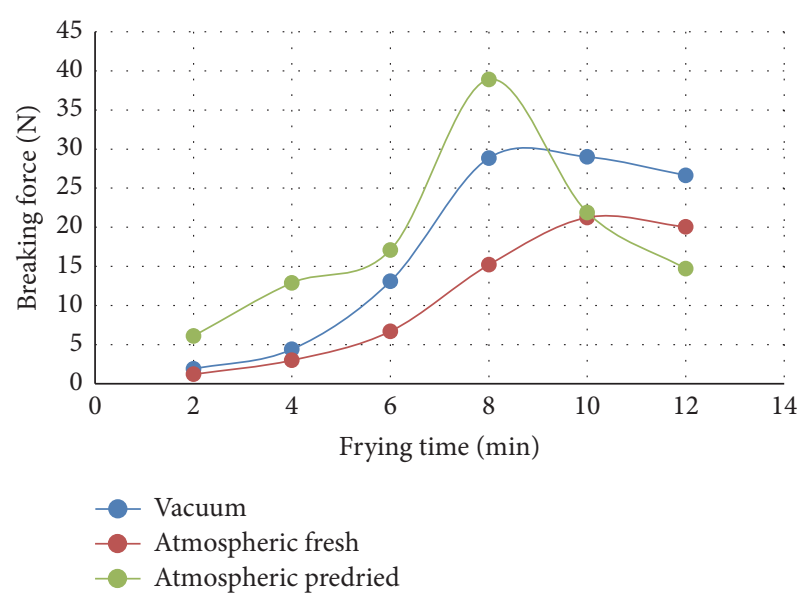

(c)

FigURE 1: Effect of frying conditions on breaking force $(\mathrm{N})$ of yellow fleshed cassava chips (YFCC) at different equivalent thermal driving forces (ETDF) of (a) $60^{\circ} \mathrm{C}$, (b) $70^{\circ} \mathrm{C}$, and (c) $80^{\circ} \mathrm{C}$.

force had been attributed to higher extent of gelatinization of the native starch of cassava at extended frying times [15] and the highest reduction observed in predried chips could be due 
TABLE 2: Kinetic parameters for quality attributes at different frying conditions.

\begin{tabular}{|c|c|c|c|c|}
\hline Quality attributes & Frying treatments & Frying temp $\left({ }^{\circ} \mathrm{C}\right)$ & $k\left(\min ^{-1}\right)$ & $R^{2}$ \\
\hline \multirow{9}{*}{ Texture (hardness) } & \multirow{3}{*}{ Vacuum } & 108 & 0.2655 & 0.95 \\
\hline & & 118 & 0.3121 & 0.89 \\
\hline & & 128 & 0.2807 & 0.83 \\
\hline & \multirow{4}{*}{ Atmospheric (fresh) } & 160 & 0.1062 & 0.18 \\
\hline & & 170 & 0.3004 & 0.88 \\
\hline & & 180 & 0.2967 & 0.91 \\
\hline & & 160 & 0.1003 & 0.56 \\
\hline & \multirow[t]{2}{*}{ Atmospheric (predried) } & 170 & 0.0936 & 0.39 \\
\hline & & 180 & 0.0972 & 0.35 \\
\hline \multirow{9}{*}{ Lightness } & \multirow{3}{*}{ Vacuum } & 108 & -0.2526 & 0.67 \\
\hline & & 118 & -0.3437 & 0.86 \\
\hline & & 128 & -0.2085 & 0.95 \\
\hline & \multirow{4}{*}{ Atmospheric (fresh) } & 160 & -0.2520 & 0.81 \\
\hline & & 170 & -0.3502 & 0.97 \\
\hline & & 180 & -0.3446 & 0.90 \\
\hline & & 160 & -0.2219 & 0.93 \\
\hline & \multirow[t]{2}{*}{ Atmospheric (predried) } & 170 & -0.3626 & 0.89 \\
\hline & & 180 & -0.4945 & 0.67 \\
\hline \multirow{9}{*}{ Redness } & \multirow{3}{*}{ Vacuum } & 108 & 0.1842 & 0.71 \\
\hline & & 118 & 0.3202 & 0.59 \\
\hline & & 128 & 0.0957 & 0.79 \\
\hline & \multirow{4}{*}{ Atmospheric (fresh) } & 160 & 0.1733 & 0.91 \\
\hline & & 170 & 0.1531 & 0.87 \\
\hline & & 180 & 0.2795 & 0.87 \\
\hline & & 160 & 0.1319 & 0.88 \\
\hline & \multirow[t]{2}{*}{ Atmospheric (predried) } & 170 & 0.1997 & 0.84 \\
\hline & & 180 & 0.5698 & 0.83 \\
\hline \multirow{9}{*}{ Yellowness } & \multirow{3}{*}{ Vacuum } & 108 & -0.1744 & 0.67 \\
\hline & & 118 & -0.5729 & 0.86 \\
\hline & & 128 & -0.2837 & 0.95 \\
\hline & \multirow{4}{*}{ Atmospheric (fresh) } & 160 & -0.3428 & 0.85 \\
\hline & & 170 & -0.4725 & 0.72 \\
\hline & & 180 & -0.2125 & 0.79 \\
\hline & & 160 & -0.6792 & 0.91 \\
\hline & \multirow[t]{2}{*}{ Atmospheric (predried) } & 170 & -0.4841 & 0.97 \\
\hline & & 180 & -0.5099 & 0.92 \\
\hline
\end{tabular}

to the reduction in moisture content before frying, leading to a high rate of crust formation [5]. Structural degradation is a resultant effect of increased moisture loss due to increase in frying oil temperatures across the all the frying methods used. Similar trend was reported by Nourian and Ramaswamy [2].

Vacuum fried chips showed a higher rate of increase in breaking force at lower frying times. This could be due to a faster rate of surface moisture removal and microstructural changes during vacuum frying. Such higher rate of moisture removal had been earlier reported by Mariscal and Bouchon [5]. However, the rapid reduction in the breaking force from 8 min frying time was the least in vacuum fried chips. This behavior could be attributed to the reduced boiling point of water at vacuum conditions and this brought about a slower rate of moisture removal throughout frying leading to reduced structural degradation and less crust formation compared to atmospheric frying. As such, vacuum fried chips were the crispiest and less crusty chips and hence could be more acceptable.

The kinetic parameters obtained for the texture parameter (hardness) are as presented in Table 2. Rate constants $k$ $\left(\mathrm{min}^{-1}\right)$ for each of the frying temperatures and activation energies $E_{a}(\mathrm{KJ} / \mathrm{mol})$ for each of the frying treatments were determined. For vacuum frying temperatures $\left(108^{\circ} \mathrm{C}, 118^{\circ} \mathrm{C}\right.$, and $128^{\circ} \mathrm{C}$ ) investigated, rate constants obtained were 0.2655 , 0.3121 , and $0.2807 \mathrm{~min}^{-1}$ while for atmospherically fried 
TABLE 3: Activation energies for different frying experiments.

\begin{tabular}{|c|c|c|}
\hline Quality attribute & Frying treatment & $\begin{array}{l}\text { Activation energy } \\
(\mathrm{kJ} / \mathrm{mol})\end{array}$ \\
\hline \multirow{3}{*}{ Texture (hardness) } & Vacuum & 53.30 \\
\hline & $\begin{array}{l}\text { Atmospheric } \\
\text { (fresh) }\end{array}$ & 1220.57 \\
\hline & $\begin{array}{l}\text { Atmospheric } \\
\text { (predried) }\end{array}$ & 37.47 \\
\hline \multirow{3}{*}{ Lightness } & Vacuum & 737.52 \\
\hline & $\begin{array}{l}\text { Atmospheric } \\
\text { (fresh) }\end{array}$ & 218.65 \\
\hline & $\begin{array}{l}\text { Atmospheric } \\
\text { (predried) }\end{array}$ & 372.17 \\
\hline \multirow{3}{*}{ Redness } & Vacuum & 587.72 \\
\hline & $\begin{array}{l}\text { Atmospheric } \\
\text { (fresh) }\end{array}$ & 557.30 \\
\hline & $\begin{array}{l}\text { Atmospheric } \\
\text { (predried) }\end{array}$ & 1720.70 \\
\hline \multirow{3}{*}{ Yellowness } & Vacuum & 584.06 \\
\hline & $\begin{array}{l}\text { Atmospheric } \\
\text { (fresh) }\end{array}$ & 446.34 \\
\hline & $\begin{array}{l}\text { Atmospheric } \\
\text { (predried) }\end{array}$ & 341.60 \\
\hline
\end{tabular}

samples (fresh and predried) the values of $0.1062,0.3004$, and $0.2967 \mathrm{~min}^{-1}$ and $0.1003,0.0936$, and $0.0972 \mathrm{~min}^{-1}$ were obtained at $160^{\circ} \mathrm{C}, 170^{\circ} \mathrm{C}$, and $180^{\circ} \mathrm{C}$, respectively. The rate constants at lower vacuum frying temperatures were higher than those obtained at their equivalent temperatures for atmospheric frying and this indicates that desired hardness of fried cassava chips could be achieved at a higher rate during vacuum frying at reduced frying temperatures. Also, the lowest values of rate constants were obtained for predried, atmospherically fried samples. The values of activation energies obtained were $53.30,1220.57$, and $37.47 \mathrm{KJ} / \mathrm{mol}$ for vacuum and atmospheric frying (fresh and predried), respectively (Table 3). The low activation energy for vacuum frying indicates that frying proceeded at lower energy requirement when compared with atmospheric frying [12] and is less sensitive to temperature changes during frying [10].

3.2. Colour Parameters (Lightness, Redness, and Yellowness and Total Colour Change). The changes observed in the colour attributes of yellow fleshed cassava slices are as presented in Figures $2-5$. Lightness $\left(L^{*}\right)$, a critical colour parameter of fried foods, is usually used as a quality control determinant and so its adequate control is of utmost importance [5]. For all the frying treatments in this study, $L^{*}$ values decreased with increase in temperature. This trend is similar to what was observed by Kumar et al. [16]. The least loss in lightness was observed during the vacuum frying of fresh slices and is greatest in fresh atmospheric fried chips. The reduction in lightness may be attributed to intense browning reaction and increase crust formation due to exposure to high temperature, especially in atmospheric fried chips. Lightness was more preserved in pretreated atmospheric fried samples compared to fresh, atmospherically fried ones. Mariscal and Bouchon [5] reported that there was no significant loss in lightness of predried and vacuum fried apple slices from 10 min frying time.

It was also observed that the rate of reduction in the values for lightness parameter at higher frying temperatures (i.e., 10 to $12 \mathrm{~min}$ ) is slower compared to the rate observed at lower frying times across all frying methods and temperatures. Similar behavior in fried potato chips was reported by Nourian et al. [17]. Since lightness is a very important colour quality parameter, lower frying temperatures (especially at vacuum conditions) with lower boiling point of water are preferable to preserve the lightness and hence the attractiveness of fried products.

Redness is an undesirable quality factor in fried foods [7]. Increase in redness shows increased crust development, resulting in lower acceptability. The increase in redness for all frying treatments may imply that all fried chips experienced increase in browning with increased frying temperature and time. This could be due to Maillard reaction resulting from the utilization of available reducing sugars [11]. Redness was highest in fresh, atmospherically fried chips. Increase in redness with increased frying temperature was the least during vacuum frying (Figure 3). Also, frying at a reduced temperature in atmospheric condition reduced the level of redness for each frying time studied. These observations are in line with the experimental results of [11]. Redness was the least in vacuum fried chips and hence could be the most preferable by consumers.

The fresh samples of cassava roots fried were yellow in colour due to fortification with carotenoids. Hence, preservation of yellowness in chips resulting from yellow fleshed cassava roots would be a desirable quality attribute of the chips and can be a major determinant for acceptance of fried yellow fleshed cassava chips. Generally, yellowness of fried chips decreased with increase in frying temperatures. It was also observed, as in lightness and redness, that yellowness had the least value for fresh atmospheric fried chips. This could be traced to the intensity of frying temperatures of untreated slices. Yellowness was the best preserved during vacuum frying and the least preserved during the atmospheric frying of fresh slices.

Vacuum fried chips had the least overall colour change compared with the atmospheric fried chips. This imply that the colour deviation of the resulting chips from the fresh slices due to processing conditions was the least in vacuum fried chips for all the frying times investigated. A similar trend had also been reported for fried apple slices by Mariscal and Bouchon [5]. Also, since the colour change is also a reflection of the extent of degradation of the total carotene content, it could further be established that vacuum fried chips had the highest total carotene retention levels. Colour changes were most pronounced in predried chips. This could be because of the initial exposure of fresh slices to drying at $80^{\circ} \mathrm{C}$ before frying and also due to a higher extent of surface crust formation. These findings agree with the report of Tran [18]. 


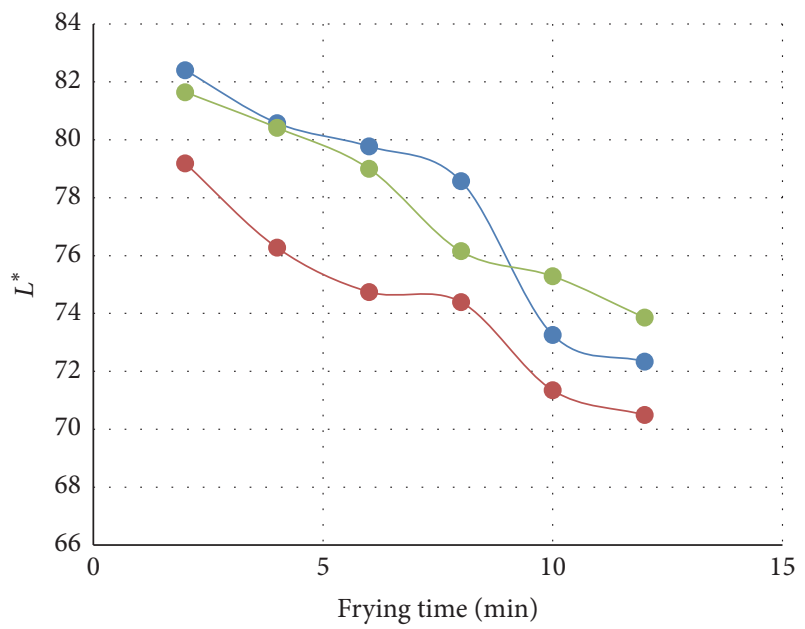

Atmospheric fresh

Atmospheric predried

Vacuum

(a)

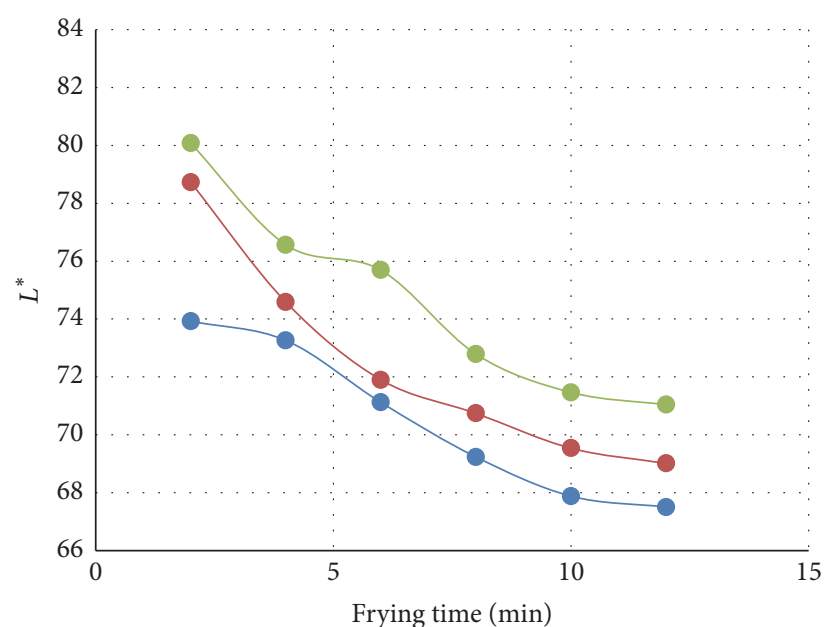

- Atmospheric fresh

Atmospheric predried

Vacuum

(b)

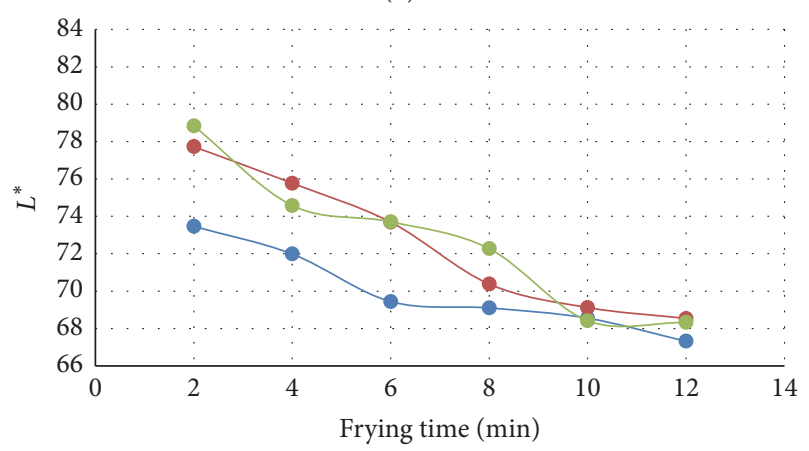

- Atmospheric fresh

Atmospheric predried

- Vacuum

(c)

FIGURE 2: Effect of frying conditions on lightness of yellow fleshed cassava chips (YFCC) at different equivalent thermal driving forces (ETDF) of (a) $60^{\circ} \mathrm{C}$, (b) $70^{\circ} \mathrm{C}$, and (c) $80^{\circ} \mathrm{C}$.

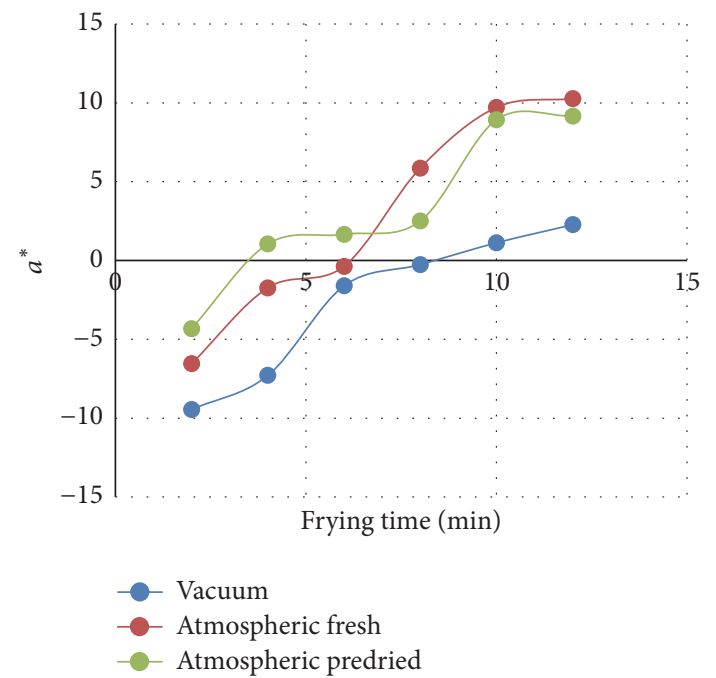

(a)

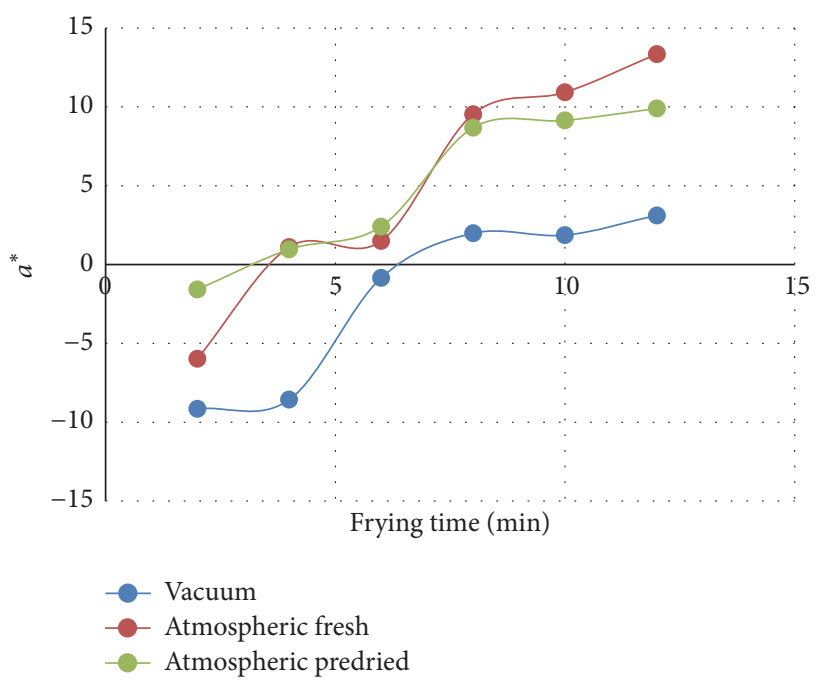

(b)

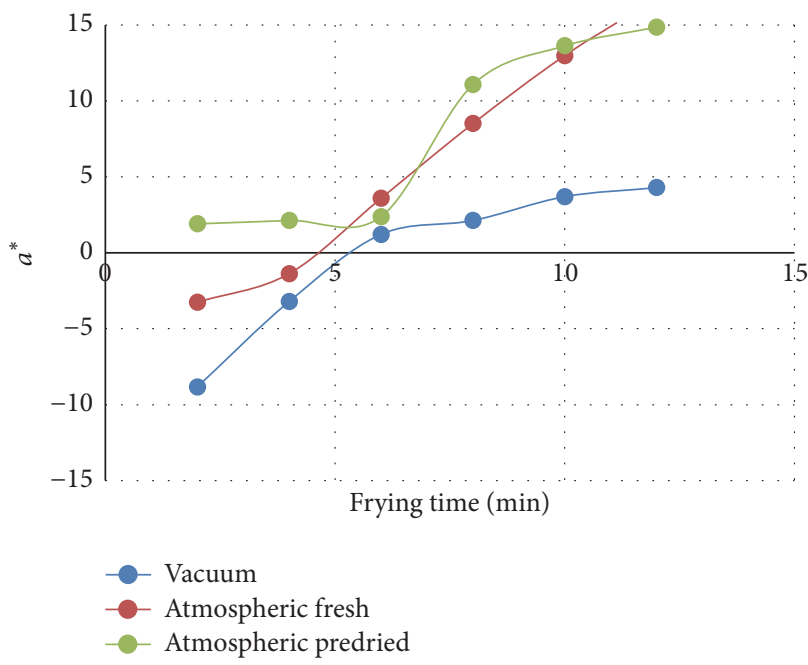

(c)

FIGURE 3: Effect of frying conditions on redness of yellow fleshed cassava chips (YFCC) at different equivalent thermal driving forces (ETDF) of (a) $60^{\circ} \mathrm{C}$, (b) $70^{\circ} \mathrm{C}$, and (c) $80^{\circ} \mathrm{C}$. 


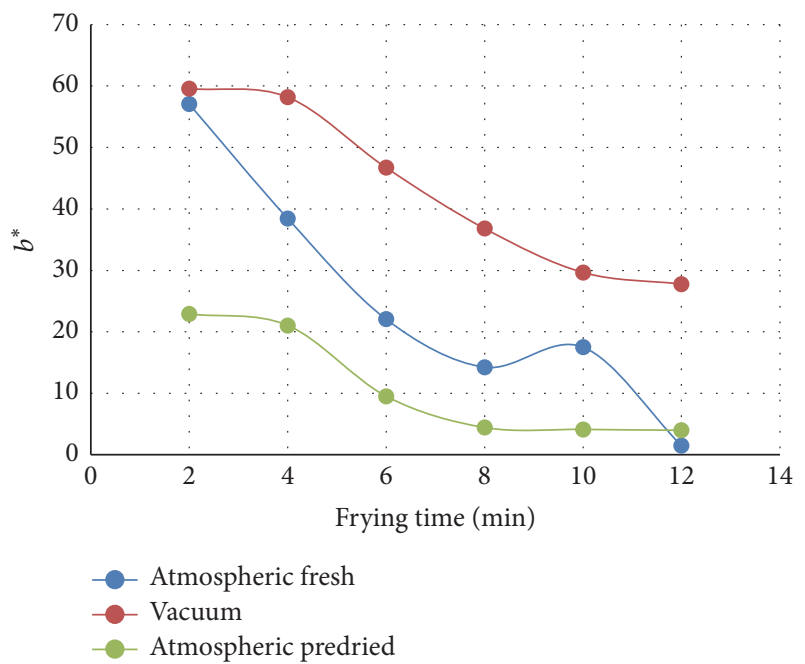

(a)

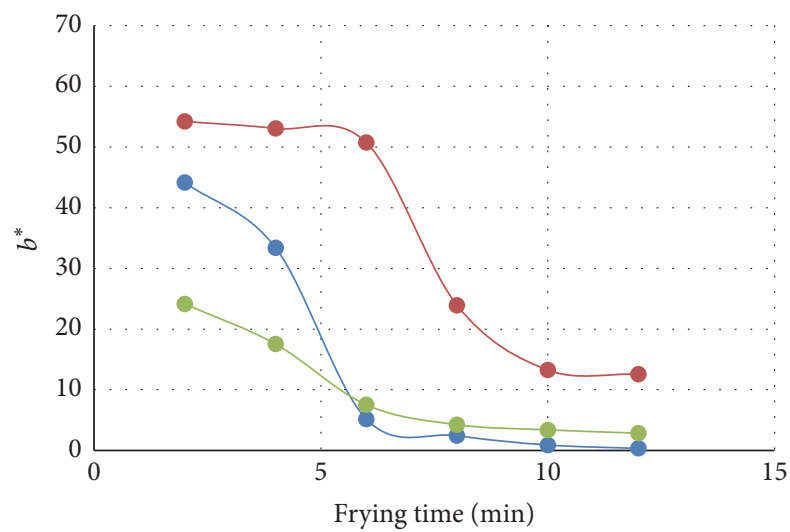

- Vacuum

- Atmospheric predried

(b)

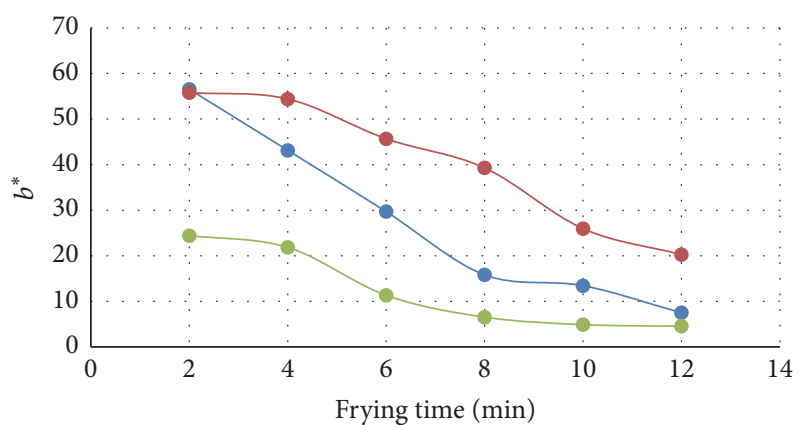

- Atmospheric fresh

- Vacuum

Atmospheric predried

(c)

FIGURE 4: Effect of frying conditions on yellowness of yellow fleshed cassava chips (YFCC) at different equivalent thermal driving forces (ETDF) of (a) $60^{\circ} \mathrm{C}$, (b) $70^{\circ} \mathrm{C}$, and (c) $80^{\circ} \mathrm{C}$.

As illustrated by the kinetic parameters presented in Table 2, despite the fact that vacuum frying was achieved at reduced frying temperature, the rate constants were close in

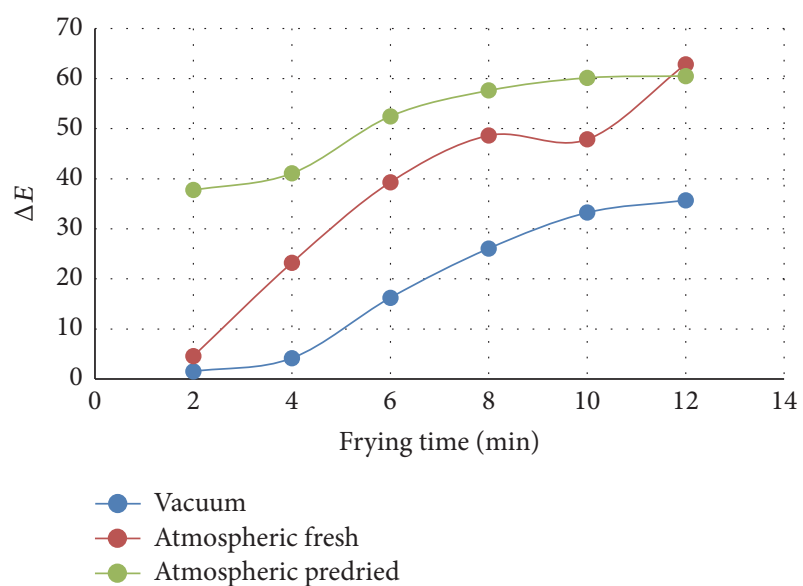

(a)

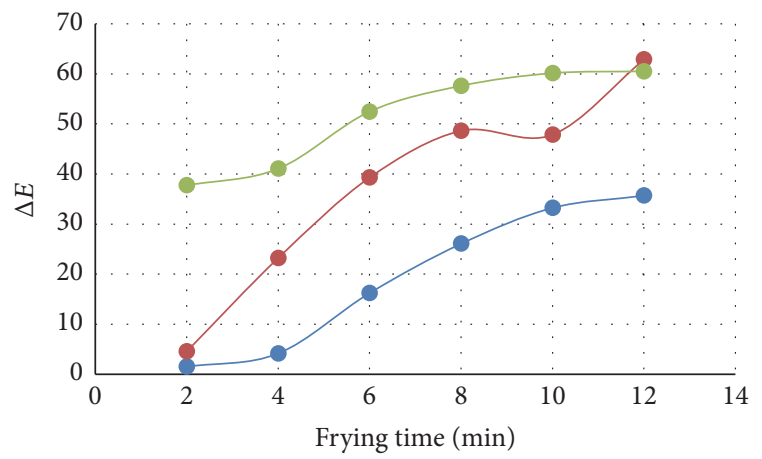

- Vacuum

Atmospheric fresh

Atmospheric predried

(b)

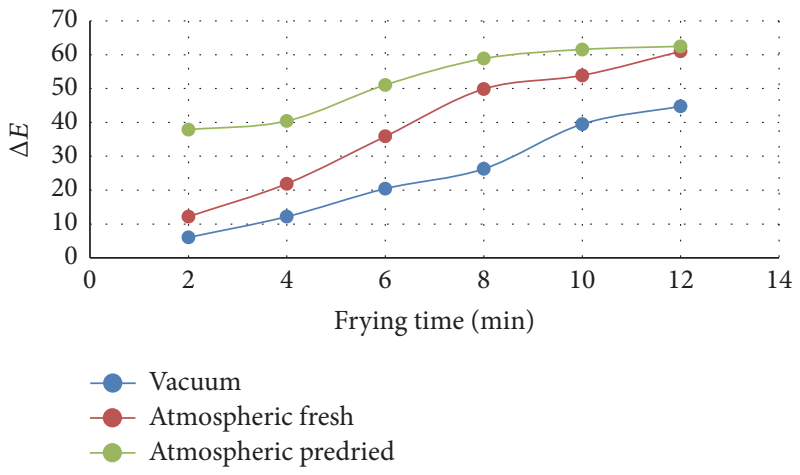

(c)

FIGURE 5: Effect of frying conditions on total colour change in yellow fleshed cassava chips at different equivalent thermal driving forces (ETDF) of (a) $60^{\circ} \mathrm{C}$, (b) $70^{\circ} \mathrm{C}$, and (c) $80^{\circ} \mathrm{C}$.

magnitude to those obtained during atmospheric frying for the colour parameters. This suggests that vacuum frying can achieve the desired changes in the quality attributes studied at reduced frying temperatures and similar rates as atmospheric frying. The kinetic parameters for the colour attributes investigated are also presented in Table 2. The trend in the values of rate constants obtained for lightness, yellowness, and overall 


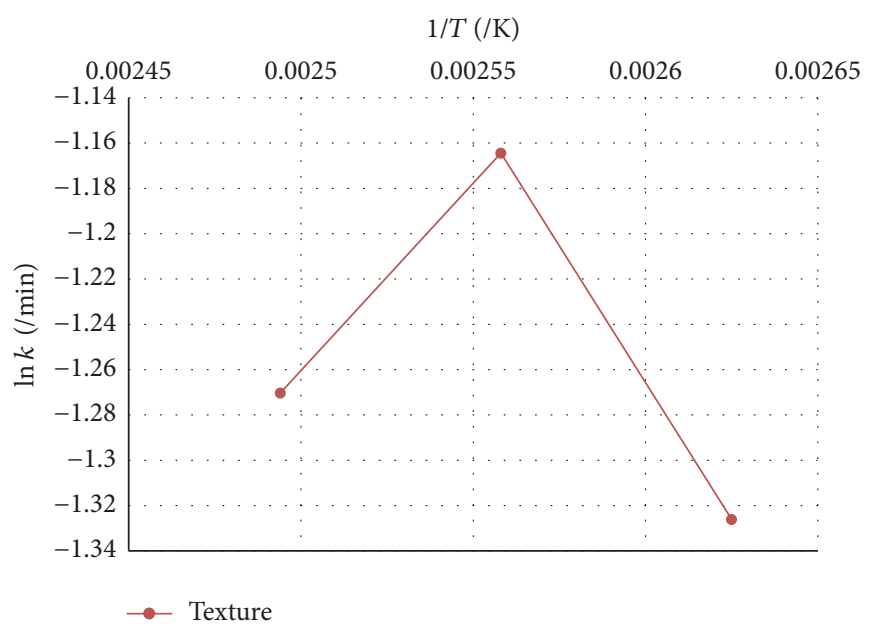

(a)

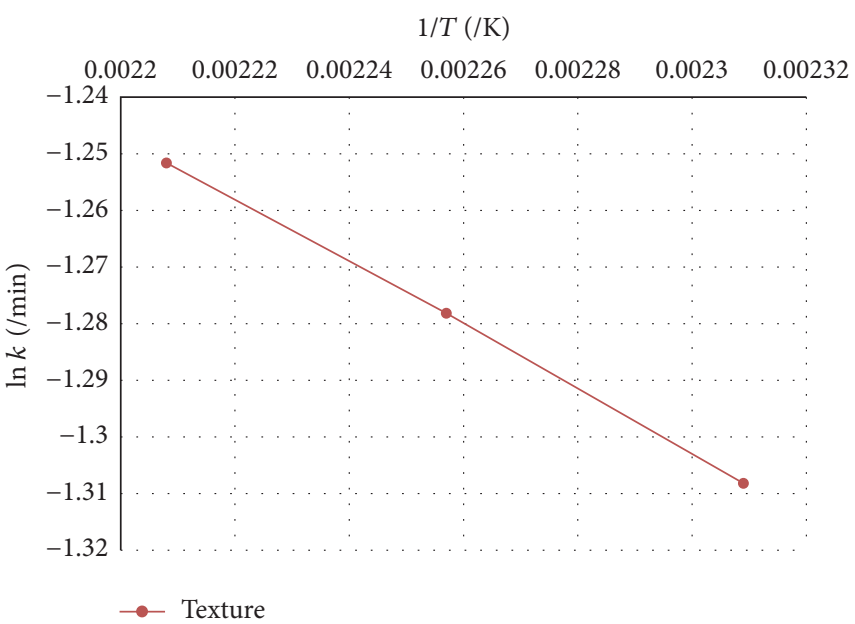

(b)

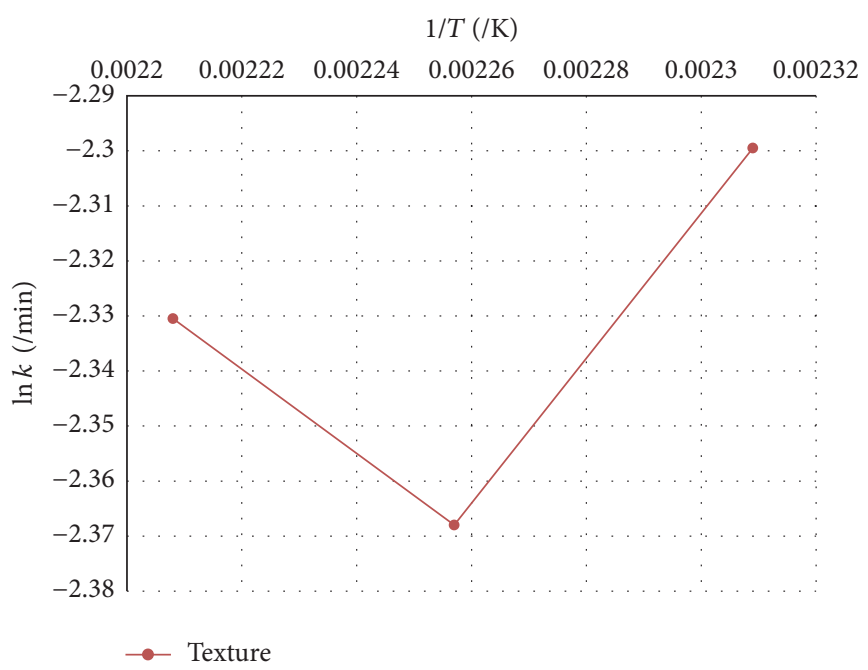

(c)

FIGURE 6: (a) Arrhenius plot relating rate constants with frying temperatures at vacuum conditions for texture (hardness) of YFCC. (b) Arrhenius plot relating rate constants with frying temperatures at atmospheric frying conditions for texture (hardness) of YFCC. (c) Arrhenius plot relating rate constants with frying temperatures at atmospheric frying conditions for texture (hardness) of predried YFCC.

colour change is because the magnitudes of these parameters generally decrease as frying temperature increases. Similar trends have been reported by Nourian et al. [17].

The plots of the temperature dependence of rate constants are as shown in Figures 6 and 7. The activation energies $\left(E_{a}\right)$ for each of the quality attributes investigated were obtained from these plots and presented in Table 3 . Since activation energy is the energy required to transform a reactant to the product by passing a transition level [9], it follows that the energy requirement for changes in hardness was the least during vacuum frying. However, for the colour parameters investigated, higher values of activation energies were obtained during vacuum frying compared to atmospheric frying. Vacuum frying is carried out at lower temperatures compared to atmospheric frying and this may lead to a slower rate of degradation of colour components in yellow fleshed cassava chips. Hence, higher activation energy could be required to achieve the desired change in colour attributes, since colour change is dependent on the surface temperature of the fried chips.

\section{Conclusions}

It could be concluded that the texture and colour parameters investigated were most preserved during vacuum frying. Also, for each of the frying temperatures, vacuum frying proceeded at equal or higher rates, as compared with atmospheric frying. In addition, the higher magnitudes of activation energies obtained for colour parameters during vacuum frying showed that the colour parameters in yellow fleshed cassava are sensitive to high processing temperatures. Vacuum frying technology could be explored in preserving texture and colour parameters of fried chips, which are the major quality attributes that influence the decision of consumers. 


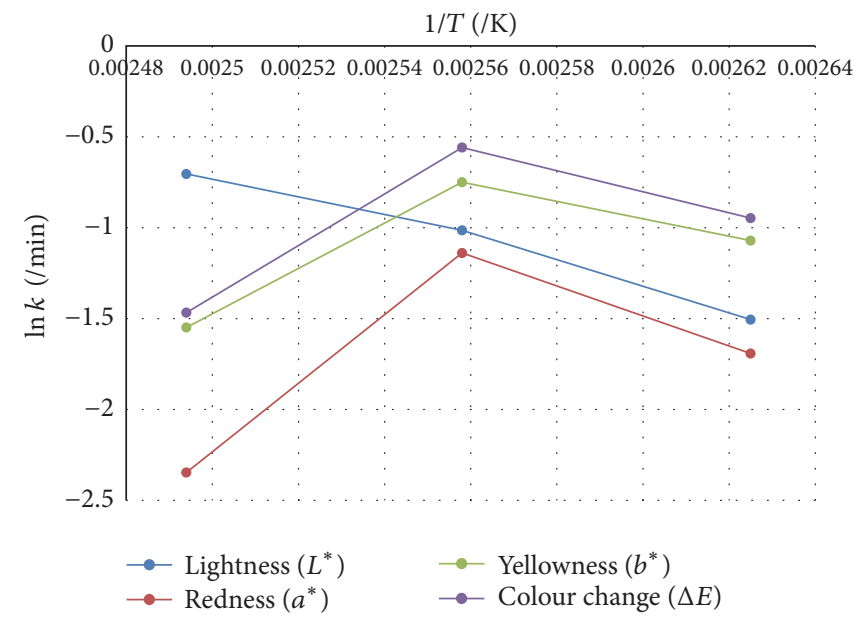

(a)

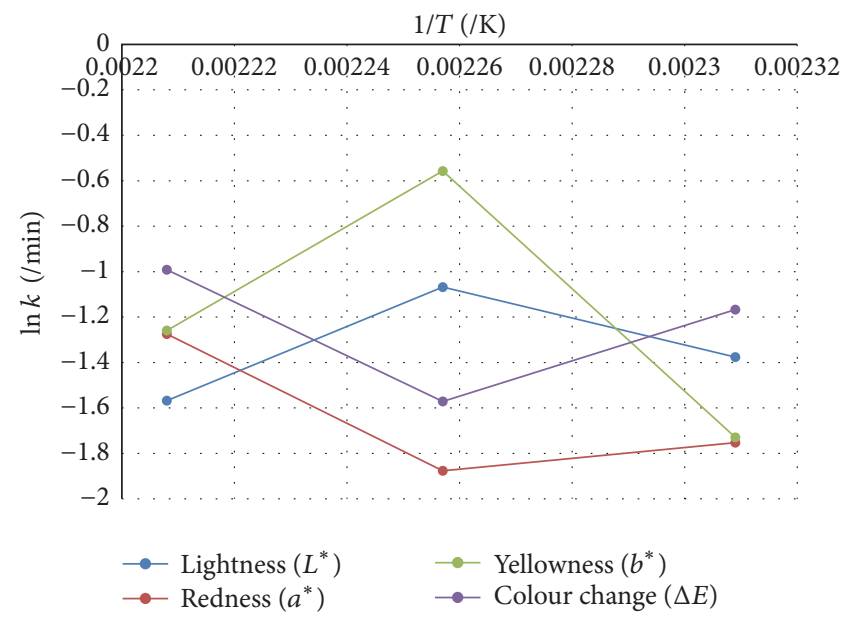

(b)

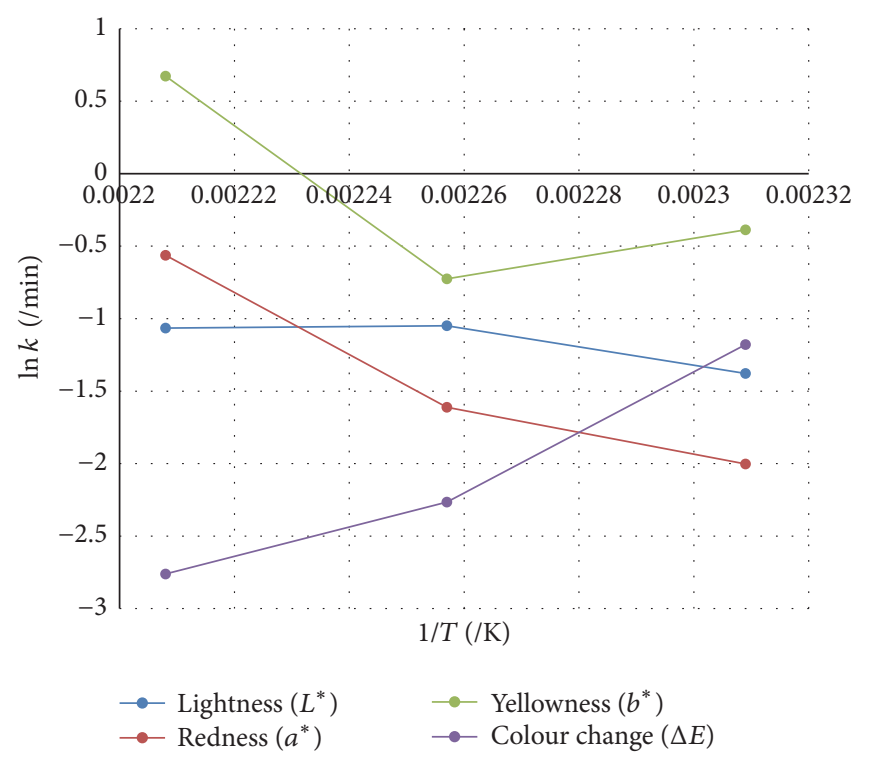

(c)

Figure 7: (a) Arrhenius plot of rate constant against frying temperatures at vacuum frying conditions for colour parameters. (b) Arrhenius plot of rate constants against frying temperatures at atmospheric frying conditions colour parameters (fresh slices). (c) Arrhenius plots of rate constants against frying temperature at atmospheric frying conditions for colour parameters (predried slices).

\section{Disclosure}

The abstract of this study was accepted for oral presentation at the 30th EFFoST International Conference held in Vienna, Austria.

\section{Conflicts of Interest}

The authors declare that there are no conflicts of interest regarding the publication of this paper.

\section{Acknowledgments}

The authors wish to thank European Commission for providing support for this research under CassavaGmarkets project and Mr. Peter Iluebbey of the Cassava Unit, International
Institute of Tropical Agriculture, Ibadan, Nigeria, for supplying the yellow fleshed cassava roots used in this work.

\section{References}

[1] V. Dueik, P. Robert, and P. Bouchon, "Vacuum frying reduces oil uptake and improves the quality parameters of carrot crisps," Food Chemistry, vol. 119, no. 3, pp. 1143-1149, 2010.

[2] F. Nourian and H. S. Ramaswamy, "Kinetics of quality change during cooking and frying of potatoes: Part I. Texture," Journal of Food Process Engineering, vol. 26, no. 4, pp. 377-394, 2003.

[3] F. Pedreschi and P. Moyano, "Effect of pre-drying on texture and oil uptake of potato chips," LWT_Food Science and Technology, vol. 38, no. 6, pp. 599-604, 2005.

[4] F. Nourian and H. S. Ramaswamy, "Kinetics of quality change during cooking and frying of potatoes: part II. Color," Journal of Food Process Engineering, vol. 26, no. 4, pp. 395-411, 2003. 
[5] M. Mariscal and P. Bouchon, "Comparison between atmospheric and vacuum frying of apple slices," Food Chemistry, vol. 107, no. 4, pp. 1561-1569, 2008.

[6] A. N. Califano and A. Calvelo, "Adjustment of surface concentration of reducing sugars before frying of potato strips," Journal of Food Processing and Preservation, vol. 12, no. 1, pp. 1-9, 1988.

[7] M. K. Krokida, V. Oreopoulou, Z. B. Maroulis, and D. MarinosKouris, "Deep fat frying of potato strips-quality issues," Drying Technology, vol. 19, no. 5, pp. 879-935, 2001.

[8] J. Garayo and R. Moreira, "Vacuum frying of potato chips," Journal of Food Engineering, vol. 55, no. 2, pp. 181-191, 2002.

[9] F. Hindra and O.-D. Baik, "Kinetics of quality changes during food frying," Critical Reviews in Food Science and Nutrition, vol. 46, no. 3, pp. 239-258, 2006.

[10] O. Vitrac, D. Dufour, G. Trystram, and A.-L. Raoult-Wack, "Characterization of heat and mass transfer during deep-fat frying and its effect on cassava chip quality," Journal of Food Engineering, vol. 53, no. 2, pp. 161-176, 2002.

[11] A. Odenigbo, J. Rahimi, M. Ngadi, D. Wees, A. Mustafa, and P. Seguin, "Quality changes in different cultivars of sweet potato during deep-fat frying," Journal of Food Processing \& Technology, vol. 3, article 156, 2012.

[12] A. B. Oyedeji, O. P. Sobukola, F. O. Henshaw, M. O. Adegunwa, L. O. Sanni, and K. I. Tomlins, "Kinetics of mass transfer during deep fat frying of yellow fleshed cassava root slices," Heat and Mass Transfer, vol. 52, no. 5, pp. 1061-1070, 2016.

[13] G. Abong, M. Okoth, E. Karuri, J. Kabira, and F. Mathooko, "Influence of potato cultivar and stage of maturity on oil content of French fries (chips) made from eight Kenyan potato cultivars," African Journal of Food, Agriculture, Nutrition and Development, vol. 9, no. 8, 2009.

[14] O. P. Sobukola, V. Dueik, and P. Bouchon, "Understanding the effect of vacuum level in structure development and oil absorption in vacuum-fried wheat starch and gluten-based snacks," Food and Bioprocess Technology, vol. 6, no. 8, pp. 20102017, 2013.

[15] O. C. Oginni, O. P. Sobukola, F. O. Henshaw, W. A. O. Afolabi, and L. Munoz, "Effect of starch gelatinization and vacuum frying conditions on structure development and associated quality attributes of cassava-gluten based snack," Food Structure, vol. 3, pp. 12-20, 2015.

[16] A. Jayendra Kumar, R. R. B. Singh, A. A. Patel, and G. R. Patil, "Kinetics of colour and texture changes in Gulabjamun balls during deep-fat frying," LWT-Food Science and Technology, vol. 39, no. 7, pp. 827-833, 2006.

[17] F. Nourian, H. S. Ramaswamy, and A. C. Kushalappa, "Kinetic changes in cooking quality of potatoes stored at different temperatures," Journal of Food Engineering, vol. 60, no. 3, pp. 257-266, 2003.

[18] M. T. T. Tran, Frying of Potato Crisps-An Investigation Aiming at Reduction Oil Content and Acrylamide Formation, ResearchSpace, Auckland, New Zealand, 2006. 

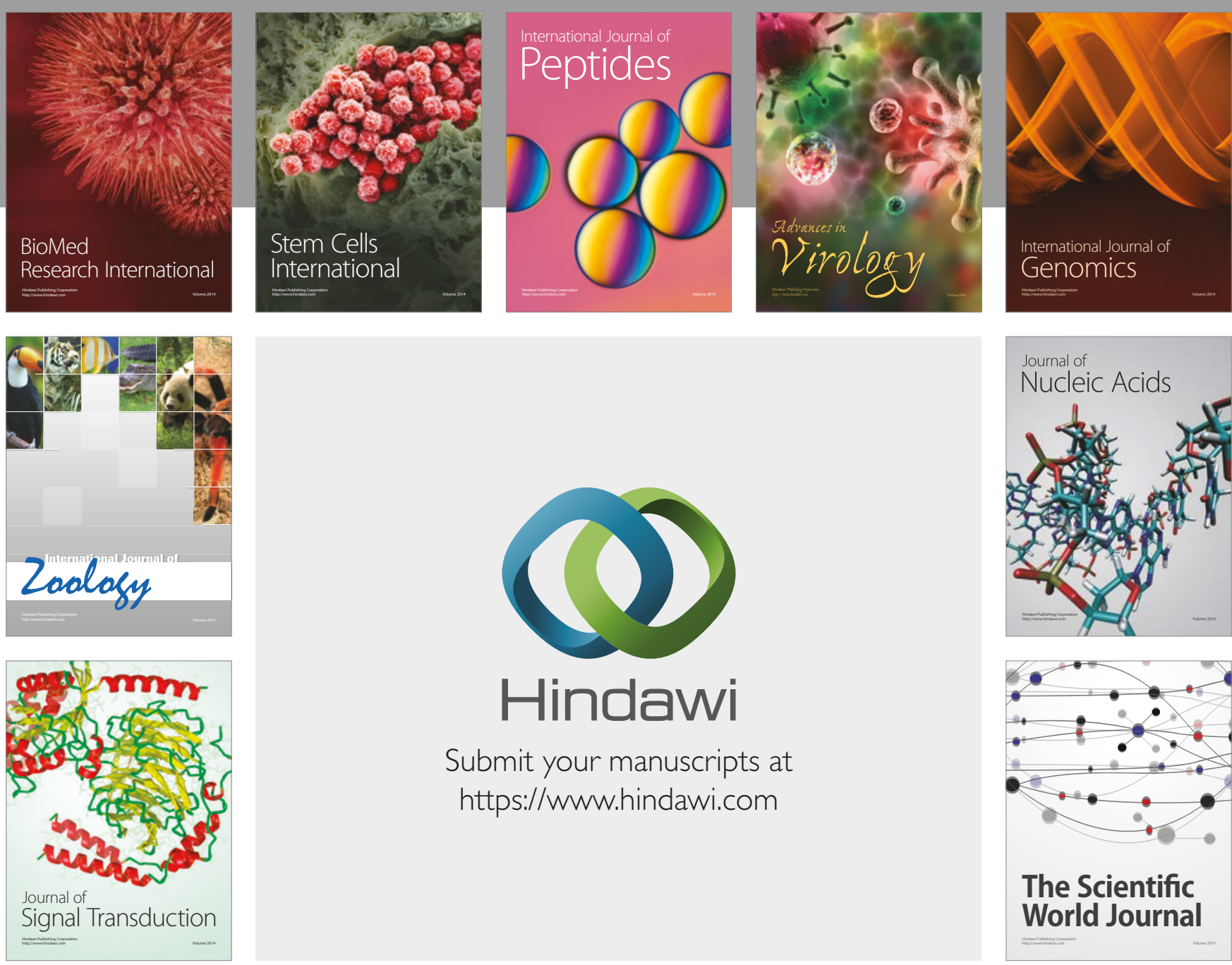

Submit your manuscripts at

https://www.hindawi.com
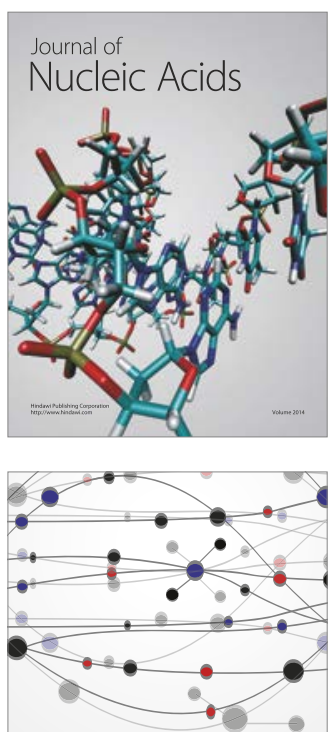

The Scientific World Journal

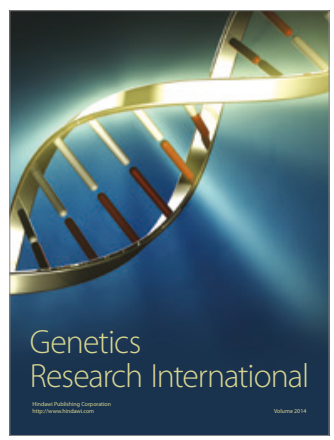

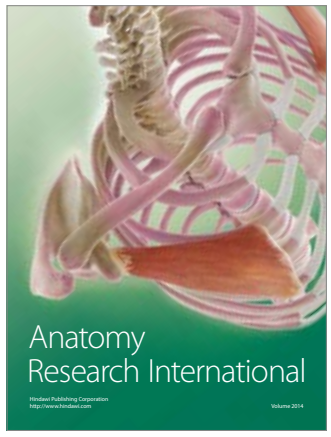

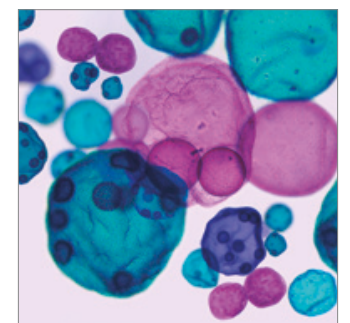

International Journal of Microbiology
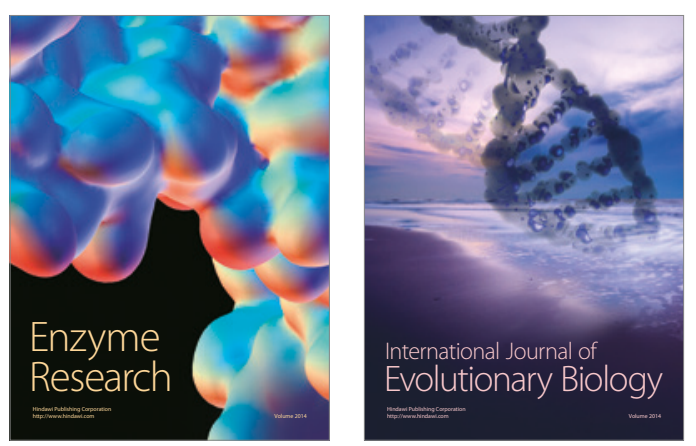
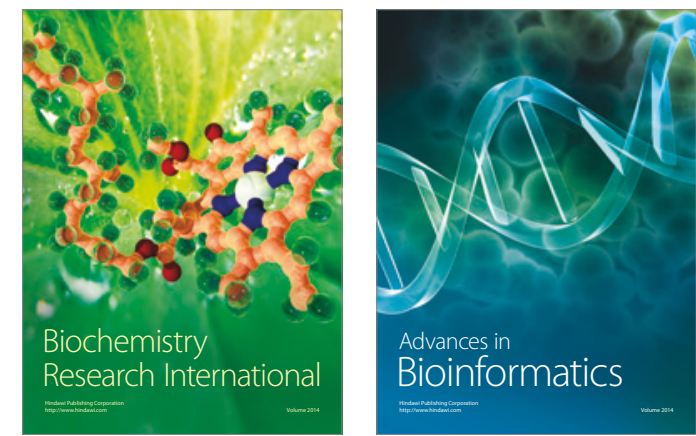

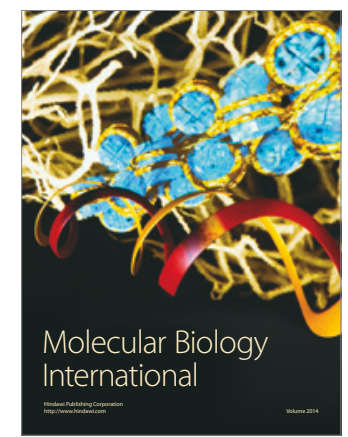

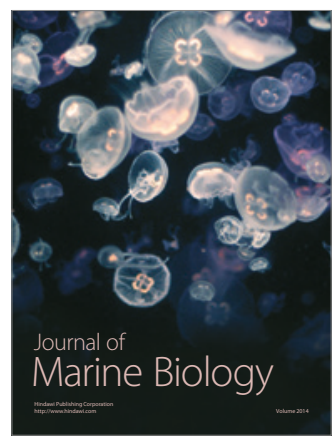

